\title{
Metal-clad-suspended self-biasing graphene modulator with tunable figure of merit
}

\author{
Jiamin Liu' ${ }^{1}$ - Zia Ullah Khan $^{1} \cdot$ Siamak Sarjoghian $^{1}$
}

Received: 8 November 2019/Accepted: 2 July 2020/Published online: 16 July 2020

(C) The Author(s) 2020

\begin{abstract}
In this letter, a research on the metal-clad-suspended self-biasing graphene modulator is conducted theoretically. The results reveal a higher light-graphene interaction for the more compact modulator. In addition, when the light-graphene interaction is enhanced, the light-metal interaction is also higher, which causes larger insertion loss and makes the figure of merit (FOM) lower. The length of $\pi$ phase shift is reduced to $6.35 \mu \mathrm{m}$ for the Mach-Zehnder modulator, which is the smallest size achieved up to date. The modulator's FOM can be tuned by changing the air gap (d) between the moveable metal plates and the suspended structure. In the case when this air gap increases, the configuration represents closer fundamental limits design. Moreover, the cut-off mode is discussed, and it has potential to be used in the tunable filter application. This tunable configuration of modulator is believed to have potential that can pave the way to design tunable light-matter interaction device and has evaluated for the near fundamental limits design.
\end{abstract}

Keywords Graphene modulators · Figure of merit · Suspended · Filter

\section{Introduction}

Graphene modulators show greater application prospect than traditional silicon modulators since it was firstly demonstrated and reported in 2011 [1]. This is because the fundamental limits [2] of graphene modulator are much

Jiamin Liu

jiamin.liu@qmul.ac.uk

1 School of Electronic Engineering and Computer Science, Queen Mary University of London, London E1 4NS, UK further than that of the modulator made by traditional materials such as silicon. Graphene has much broader and deeper tunable absorption [3] and ultrahigh mobility [4, 5] in the wide band wavelength from visible light to $\mathrm{THz}$ band for the interested electro-modulation and absorption. Till now, all the figure of merits (FOMs) of modulator made by graphene, such as modulation depth, modulation speed, operation bandwidth, footprint, and modulation efficiency are much better and far beyond than that of traditional modulators.

In this field, in order to realize near fundamental limits designing, different modulator structures are put forward [6-10]. The main purpose is to enhance the light-graphene interaction. Researchers have found that the symmetrical structure [6,7] can make the mode with lower insertion loss and higher modulation depth, so the light-graphene interaction is enhanced further. The figure of merit (FOM) of graphene modulator is defined as the ratio of modulation depth to insertion loss. And the FOM can be an index of how the design is approaching the fundamental limits (it's a relation between insertion loss and modulation depth, as described in Ref. [2]) of graphene modulator.

In our recently work [11-13], we have reported the suspended graphene modulators which are already much near the fundamental limits of graphene modulator. The FOMs of these cases are in the order of 2000 [11-13] and the contradiction between modulation speed and modulation efficiency is reduced significantly. These results are contributed by that the devices are very clean and the modes are symmetrical. However, the modulator which is between low design and near fundamental limits design is still a gap which should be addressed.

In this letter, we show how near fundamental limits design happens. Here, a suspended self-biasing graphene modulator with tunable metal cladding is investigated. The 
light-graphene interaction is very complex and can be enhanced and tuned significantly by very small modulation size. The modulation depth and insertion loss are increasing with considered smaller modulation size. The FOM is changeable by different insulator thicknesses and tunable by moveable metal cladding. However, when the modulation size is too small, the mode will be cut-off and the loss is huge. The trade-off between modulation depth and FOM is analyzed and the filter application by cut-off wavelength is also discussed. We find that when the air gap $(d)$ between moveable metal cladding and suspended structure is larger, the design is nearer to the fundamental limits of graphene modulator. However, we can control the tunable lightgraphene interaction by smaller air gap $(d)$.

\section{Results and discussions}

The structure of metal-clad-suspended self-biasing graphene modulator is shown in Fig. 1a.

For this structure, two monolayer graphene sheets are sandwiched by an insulator slab (here aluminum oxide $\mathrm{Al}_{2} \mathrm{O}_{3}, \varepsilon_{1}=3.06$ at $\left.\lambda=1.55 \mu \mathrm{m}\right)$. These two graphene sheets are biased by each other and suspended in the air. Two moveable metal plates (here copper is adopted, the permittivity $\varepsilon_{3}$ is got from Drude model) are cladding above or below both sides of the suspended structure. The active area of the modulator includes seven layers: the moveable upper and below metal plates $\left(\varepsilon_{3}\right)$, the two air gaps $\left(\varepsilon_{2}\right)$ with distance $d$ is shown in the figure, two graphene sheets (permittivity is $\varepsilon_{\mathrm{g}}=\mathrm{i} \sigma_{\mathrm{g}} / \omega \varepsilon_{0} \delta[14,15]$, where the surface conductivity $\sigma_{\mathrm{g}}$ is calculated from Kubo formula [16], $\delta=0.33 \mathrm{~nm}$ is the thickness of the monolayer graphene), and the middle insulator slab $\left(\mathrm{Al}_{2} \mathrm{O}_{3}\right)$ with thickness $w$. Here the air gap $(d)$ between metal cladding and the suspended structure is tunable by moving the metal plates. The corresponding axis system is also shown in Fig. 1a, the modulator width in $y$-direction is large enough for the beam width diffraction which doesn't have boundary and can be assumed to be the same as in free- space. The optical wave (here $\lambda=1.55 \mu \mathrm{m}$ ) incidents in $z$ direction which is perpendicular to $x-y$ plane.

The methodology here is to derive the mode field equations and the dispersion equation of this symmetrical seven-layer structure for TE mode which has been used and discussed in detail in reference [12]. This is the well-known two-dimensional analysis [17].

Figure 2 shows the mode power attenuation (MPA, $\alpha$ ) as a function of chemical potential of graphene $\left(\mu_{\mathrm{c}}\right)$ when insulator $\left(\mathrm{Al}_{2} \mathrm{O}_{3}\right)$ slab thickness is $w=100 \mathrm{~nm}$ and air gap width is $d=500 \mathrm{~nm}$ (black solid line), $300 \mathrm{~nm}$ (red dashed line) or $250 \mathrm{~nm}$ (blue dotted line) at $\lambda=1.55 \mu \mathrm{m}$.

There shows an off-state MPA $\left(\alpha_{\text {off }}\right)$ and an on-state MPA $\left(\alpha_{\text {on }}\right)$ and a modulation depth of $\Delta \alpha=\alpha_{\text {off }}-\alpha_{\text {on }}$. At the absorption threshold point of graphene $\left(\mu_{\mathrm{c}}=0.4 \mathrm{eV}\right.$ here), the mode transfers from off-state to on-state when the chemical potential is slightly higher. This is because when the chemical potential is lower than half photon energy $(0.4 \mathrm{eV}$ for $\lambda=1.55 \mu \mathrm{m})$, the graphene causes interband absorption, otherwise, only intraband absorption happens which causes very small loss.

Here, the insulator slab has a thickness of $w=100 \mathrm{~nm}$. However, when the air gap width changes from $d=500 \mathrm{~nm}$ to $d=250 \mathrm{~nm}$ the modulation depth increase from $\quad 0.4339 \mathrm{~dB} / \mu \mathrm{m} \quad\left(\alpha_{\text {off }}=0.4368 \mathrm{~dB} / \mu \mathrm{m}, \quad \alpha_{\text {on- }}\right.$ $=0.0029 \mathrm{~dB} / \mu \mathrm{m}$ for $d=500 \mathrm{~nm})$ to $1.2388 \mathrm{~dB} / \mu \mathrm{m}\left(\alpha_{\text {off- }}\right.$ $=1.2754 \mathrm{~dB} / \mu \mathrm{m}, \alpha_{\mathrm{on}}=0.0366 \mathrm{~dB} / \mu \mathrm{m}$ for $\left.d=250 \mathrm{~nm}\right)$, respectively. The light-graphene interaction is much better enhanced when the air gap width $d$ is smaller. The normalized insertion loss is $\alpha_{\text {on }}$, so the FOM of this modulator can be defined as [8]:

$\mathrm{FOM}=\Delta \alpha / \alpha_{\text {on }}$

For $d=500 \mathrm{~nm}$ and $d=250 \mathrm{~nm}$, we get the value of FOM of 150 and 34, respectively. So when the light-graphene interaction is enhanced, we get the modulation depth but loss the FOM for much larger insertion loss caused by the metal plates (larger light-metal interaction).

From the inset of Fig. 2, the corresponding mode index ( $\left.N_{\text {eff }}\right)$ for each case can be noted. When $d$ is smaller, $N_{\text {eff }}$ is
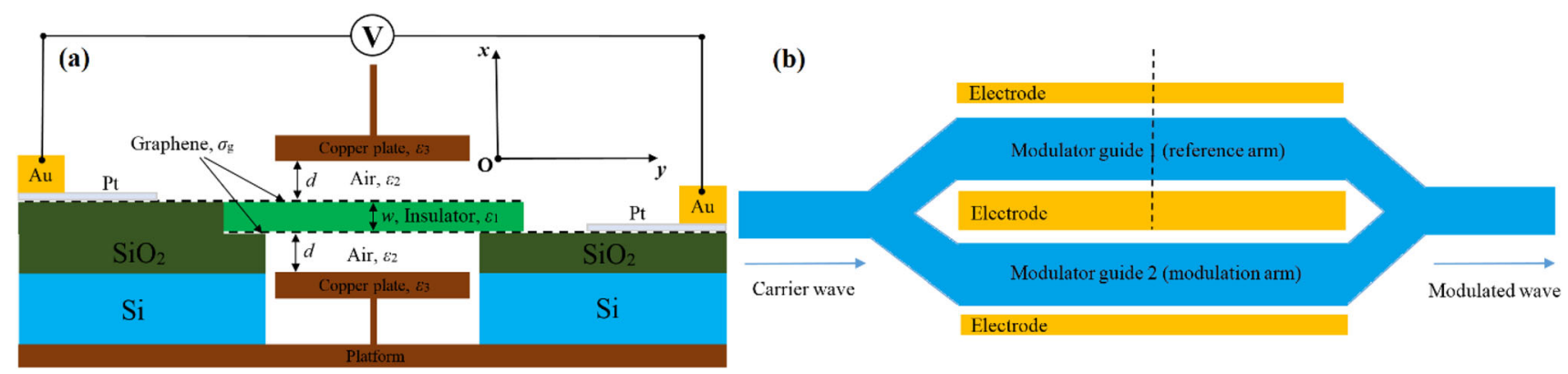

Fig. 1 a Cross section schematic of the structure of metal-clad-suspended self-biasing graphene modulator. b Schematic of Mach-Zehnder modulator 


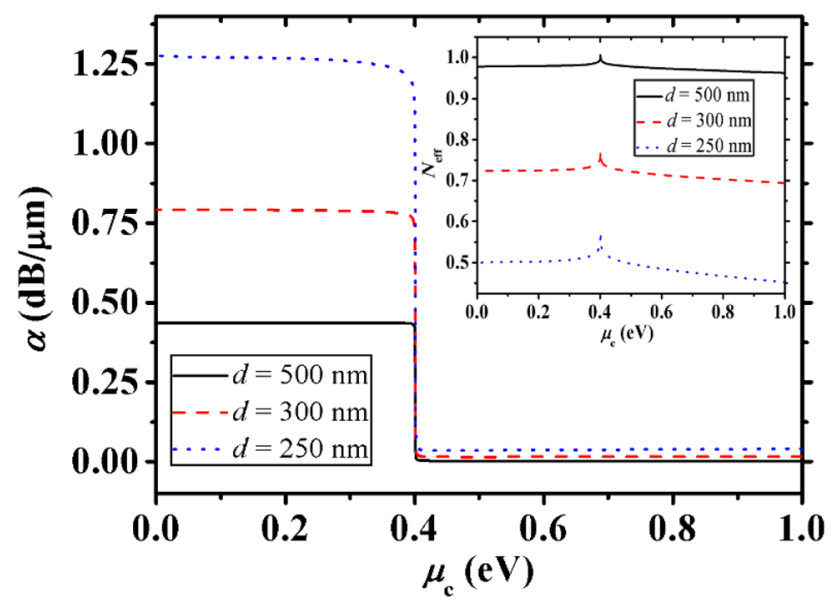

Fig. 2 MPA $\alpha$ of the modulator is gotten as a function of chemical potential $\mu_{\mathrm{c}}$ when $w=100 \mathrm{~nm}$ and $d=500 \mathrm{~nm}$ (black solid line), $300 \mathrm{~nm}$ (red dashed line) and $250 \mathrm{~nm}$ (blue dotted line) at wavelength $\lambda=1.55 \mu \mathrm{m}$. The inset shows the corresponding effective refractive index $\left(N_{\text {eff }}\right)$ of the mode as a function of $\mu_{\mathrm{c}}$ (color figure online)

much lower than 1 for much larger light-metal interaction. The change of mode index $\left(\Delta N_{\text {eff }}\right)$ is $0.04365,0.07736$, and 0.12200 for $d=500 \mathrm{~nm}, 300 \mathrm{~nm}$, and $250 \mathrm{~nm}$ respectively. If two of this modulator are used as two arms of Mach-Zehnder $(\mathrm{M}-\mathrm{Z})$ modulator, the $\pi$-phase shift length will be only $17.75 \mu \mathrm{m}, 10.02 \mu \mathrm{m}$, and $6.35 \mu \mathrm{m}$ accordingly at $\lambda=1.55 \mu \mathrm{m}$. This is a great improvement for $\mathrm{M}-\mathrm{Z}$ modulator. The schematic of the $\mathrm{M}-\mathrm{Z}$ modulator is shown in Fig. 1b. Two arms of this waveguide are used: One is the reference arm (modulator guide 1) with a fixed applied voltage (chemical potential); one is the modulation arm (modulator guide 2) with a changeable applied voltage (information signal). The carrier wave is split at the left port and converged at the right port.

Figure 3 shows the modulation depth and FOM as a function of insulator thickness $\mathrm{w}$ when air gap width $d=500 \mathrm{~nm} \quad$ (a) and $300 \mathrm{~nm} \quad$ (b) at wavelength $\lambda=1.55 \mu \mathrm{m}$ :

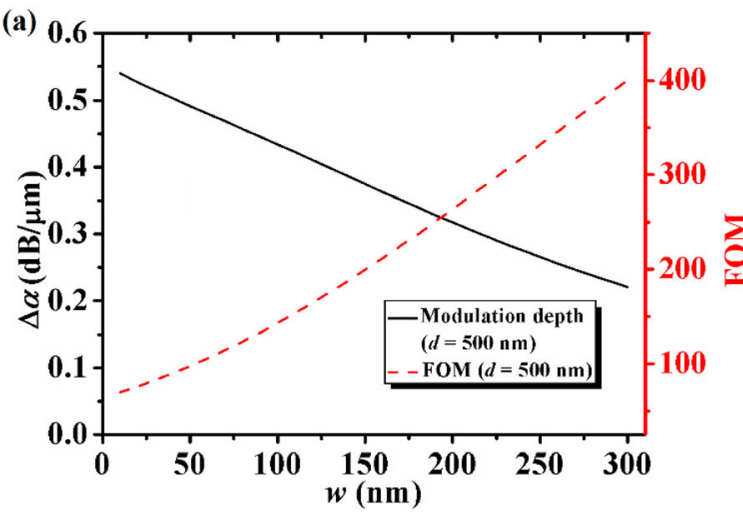

From Fig. 3, we can see for both cases, the modulation depth decreases and FOM increases as $\mathrm{w}$ is becoming larger, so the thinner w can cause higher light-graphene interaction, but it also causes higher insertion loss for higher light-metal interaction. For $d=500 \mathrm{~nm}$, the modulation depth is in the scale of $0.54 \sim 0.22 \mathrm{~dB} / \mu \mathrm{m}$ $(1.94 \sim 0.24 \mathrm{~dB} / \mu \mathrm{m}$ for $d=300 \mathrm{~nm})$ and the corresponding FOM is in the scale of $70 \sim 400(25 \sim 92$ for $d=300 \mathrm{~nm})$ when $w$ is changing from 10 to $300 \mathrm{~nm}(50$ $300 \mathrm{~nm}$ for $d=300 \mathrm{~nm}$ ). Therefore, there is a trade-off between higher modulation depth and higher FOM. If the modulation depth is got, the modulation efficiency will loss for larger insertion loss and the design will be further away from the fundamental limits of graphene modulator. According to our calculation, we find for $d=300 \mathrm{~nm}$, the mode is cut-off when $w$ is lower than $50 \mathrm{~nm}$. The cut-off wavelength $\left(\lambda_{\mathrm{c}}\right)$ has a relation of [18]:

$f_{\mathrm{c}}=\frac{c}{\lambda_{\mathrm{c}}}=\frac{c}{2\left(n_{1} w+2 d\right)}$

here $c=3 * 10^{8} \mathrm{~m} / \mathrm{s}$ is velocity of light in vacuum, $n_{1}=$ $\sqrt{\varepsilon_{1}}$ is the refractive index of the insulator material $\left(n_{1}=1.75\right.$ for $\left.\varepsilon_{1}=3.06\right),\left(n_{1} w+2 d\right)$ is the optical interval between two metal plates. From Eq. (2), we can change it to:

$w_{c}=\frac{\lambda}{2 n_{1}}-\frac{2 d}{n_{1}}$

We submit $\lambda=1.55 \mu \mathrm{m}, n_{1}=1.75$ and $d=300 \mathrm{~nm}$ to Eq. (3), and get $w_{\mathrm{c}}=100 \mathrm{~nm}$, which is why when $w<50 \mathrm{~nm}$, the loss become huge. When the mode is cutoff, the light-metal interaction will be extremely high which will cause much higher insertion loss and much lower FOM even though the modulation depth may be enhanced.

The applied voltage should be higher $(\sim 20 \mathrm{~V})$ when $\mathrm{Al}_{2} \mathrm{O}_{3}$ is used as the gate material. If we use thinner gate material, the modulation depth is enhanced, however, the

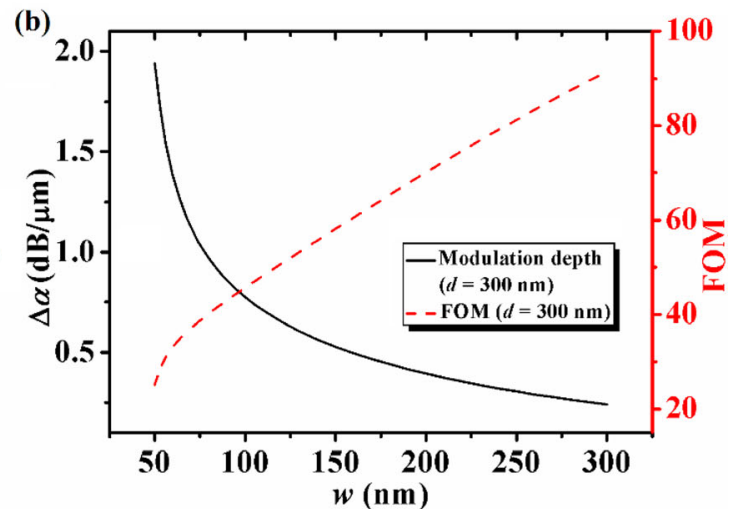

Fig. 3 Modulation depth (black solid line) and FOM (red dashed line) as a function of insulator thickness $w$ when air gap width $d=500 \mathrm{~nm}$ (a) and $300 \mathrm{~nm}$ (b) at wavelength $\lambda=1.55 \mu \mathrm{m}$ (color figure online) 
FOM will loss as shown in Fig. 3. According to our calculation, if we use high- $\kappa$ gate material [19], the contradiction between modulation depth and FOM will be reduced significantly. For example, if $\mathrm{Ta}_{2} \mathrm{O}_{5}\left(\varepsilon_{1}=22\right)$ is adopted as the gate material, we choose $w=30 \mathrm{~nm}$, $d=500 \mathrm{~nm}$, the applied voltage can be only $V_{\text {off }}$ $(0.3 \mathrm{eV})=0.37 \mathrm{~V}, V_{\text {on }}(0.5 \mathrm{eV})=1.0 \mathrm{~V}$, and the modulation depth is $0.56 \mathrm{~dB} / \mu \mathrm{m}$ with a FOM of 694 , which are all much better values. Therefore, high- $\kappa$ gate material is much better to fabricate this modulator. In this case, we can get an energy consumption as low as $\sim 1 \mathrm{fJ} /$ bit according to our calculation.

We get the modulation depth and FOM as a function of air gap width $d$ when $w=100 \mathrm{~nm}$ at $\lambda=1.55 \mu \mathrm{m}$, as shown in Fig. 4:

As it can be observed that the modulation depth is much higher at lower $d$ which enhances the light-graphene interaction. However, the light-metal interaction is also enhanced which causes higher insertion loss and lower FOM. Since $d$ is changeable by moving the metal cladding, we can achieve tunable FOM for this modulator. When $d$ is too small, the mode will also be cut-off. From Eq. (2), the relation of cut-off $d_{\mathrm{c}}$ can be derived as:

$d_{\mathrm{c}}=\frac{\lambda}{4}-\frac{n_{1} w}{2}$

when $\lambda=1.55 \mu \mathrm{m}, n_{1}=1.75$ and $w=100 \mathrm{~nm}$, we get $d_{\mathrm{c}}=300 \mathrm{~nm}$. Even for lower value of $d$, the loss will be even high. Therefore, when $d$ is larger, nearer fundamental limits design can be achieved.

In order to get a better knowledge of light-matter interaction, the mode fields of the modulator are calculated as a function of $x$-axis, as shown in Fig. 5.

It can be observed that the mode confinement will be absolutely better when $d$ is lower. This is because for TE mode, the metal plate will confine the field for it is always

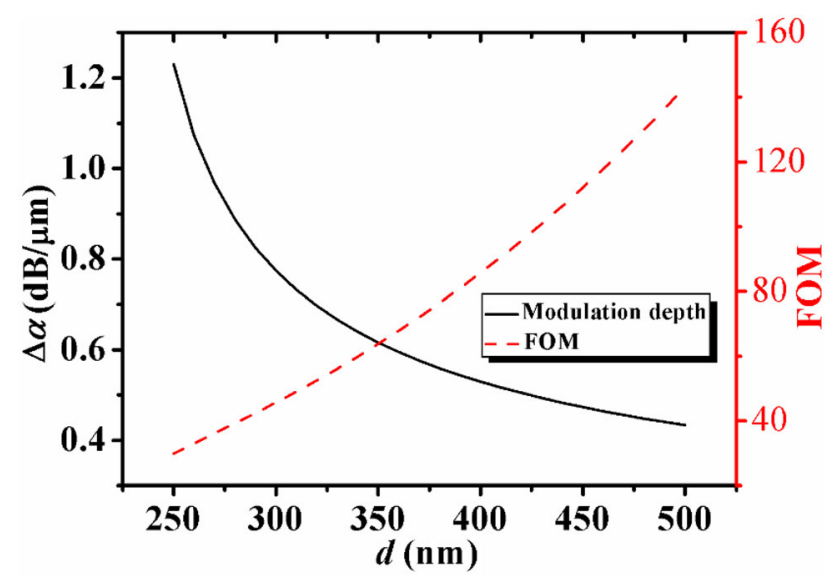

Fig. 4 Modulation depth (black solid line) and FOM (red dashed line) as a function of air gap width $d$ when insulator thickness $w=100 \mathrm{~nm}$ at wavelength $\lambda=1.55 \mu \mathrm{m}$ (color figure online)

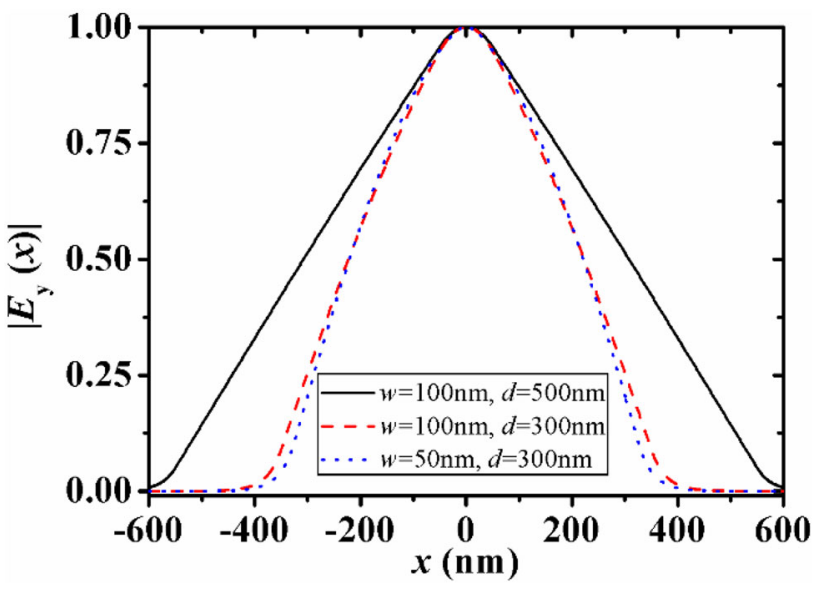

Fig. 5 Mode field distributions as a function of $x$-axis when $w=100 \mathrm{~nm}, d=500 \mathrm{~nm}$ (black solid line); $w=100 \mathrm{~nm}$, $d=300 \mathrm{~nm}$ (red dashed line); $w=50 \mathrm{~nm}, d=300 \mathrm{~nm}$ (blue dotted line) at wavelength $\lambda=1.55 \mu \mathrm{m}$ (color figure online)

E-field near at the interface of metal. When $w$ is lower, according to our calculation, we find the mode amplitude (A) in graphene layer is higher ( $A$ is 0.948 for $w=100 \mathrm{~nm}$, and 0.985 for $w=50 \mathrm{~nm}$ ). As the confinement of the mode will enhance the photon number which interact with graphene and the amplitude in graphene layer may enhance the interaction strength of one photon, the light-graphene interaction will absolutely be enhanced by lower $d$ and lower $w$. However, the light-metal interaction is also enhanced by lower $d$ and lower $w$ for larger evanescent depth.

The transmittance and the modulation performance are gotten as a function of carrier wavelength according to $T(\lambda)=\operatorname{Exp}[-\alpha L]$ when $L=5 \mu \mathrm{m}$ is the modulator length, as shown in Fig. 6:

For $w=100 \mathrm{~nm}$ and $d=500 \mathrm{~nm}$, the insertion loss can be very low at the interested wavelength $\left(T_{\max }=0.995\right)$, but the modulation depth is lower for this case (only $50 \%)$. However, for other two cases, the modulation depth can be higher $(\sim 77 \%)$ but the insertion loss is also higher. When the wavelength is too large, the mode will be cut-off, here we can see the calculated cut-off wavelength is $\lambda_{\mathrm{c} \text { - }}$ $=2.68 \mu \mathrm{m}, 1.89 \mu \mathrm{m}$ and $1.62 \mu \mathrm{m}$ for these three cases accordingly. The wavelength which is larger than $\lambda_{\mathrm{c}}$ will be filtered accordingly. According to Eq. (2), it can be changed to $\lambda_{\mathrm{c}}$ form as:

$\lambda_{\mathrm{c}}=2\left(n_{1} w+2 d\right)$

for these three cases, the achieved theoretical cut-off wavelength is $\lambda_{\mathrm{c}}=2.35 \mu \mathrm{m}, 1.55 \mu \mathrm{m}$ and $1.375 \mu \mathrm{m}$. The calculation results show slightly red shift but agree with the theory value very well.

The full-wave simulation using commercial software (COMSOL) is conducted, which shows good agreement with 


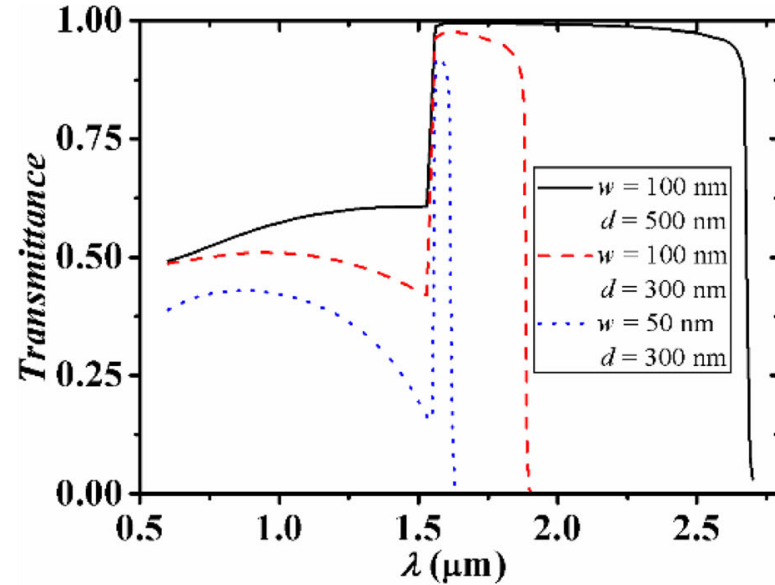

(a)

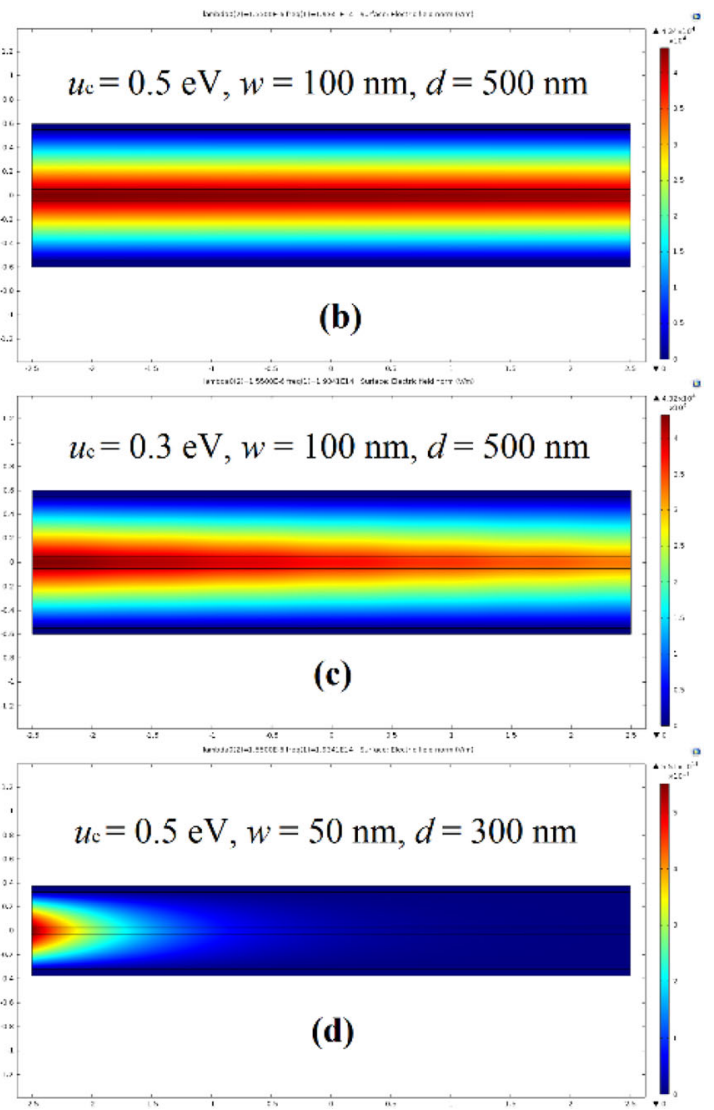

longitudinal direction at different structure parameters: b $w=100 \mathrm{~nm}, d=500 \mathrm{~nm}$ at $\mu_{\mathrm{c}}=0.5 \mathrm{eV} ;$ c $w=100 \mathrm{~nm}$, $d=500 \mathrm{~nm}$ at $\mu_{\mathrm{c}}=0.3 \mathrm{eV} ; \mathbf{d} w=50 \mathrm{~nm}, d=300 \mathrm{~nm}$ at $\mu_{\mathrm{c}}=0.5 \mathrm{eV}$ (color figure online)

and lower air gap width $d$. However, the light-metal interaction is also stronger with smaller size which causes larger insertion loss and makes lower FOM. The change of mode index $\left(\Delta N_{\text {eff }}\right)$ can be as high as 0.12200 causing a $\pi$-phase shift length of only $6.35 \mu \mathrm{m}$ for M-Z modulator which is the best value up to date. The FOM is tunable by changing the air gap (d) between the moveable metal plates and the suspended structure. When the air gap is larger, this configuration shows nearer fundamental limits design. The mechanism of lightgraphene interaction is analyzed by the mode field distribution. Moreover, the cut-off mode is discussed by showing $w_{\mathrm{c}}$, $d_{\mathrm{c}}$ and $\lambda_{\mathrm{c}}$, and the tunable filter application is mentioned. At the end, we show a 2D mode profile in the longitudinal transmission direction by COMSOL simulation, which matches our calculation results. We believe these results are very useful to design tunable light-matter interaction devices and contribute to tunable FOM physics.

In order to get a better knowledge of how nearer fundamental limits of graphene modulator happens, the FOMs of related graphene modulators are summarized as comparison in Table 1: 
Table 1 Comparison with other modulators

\begin{tabular}{lllllll}
\hline Refs. & Modulation speed & Extinction ratio & Energy-per-bit & FOM $(\Delta \alpha / \alpha)$ & Footprint & Insertion loss \\
\hline$[1]$ & $1.2 \mathrm{GHz}$ & $0.1 \mathrm{~dB} / \mu \mathrm{m}$ & $\mathrm{NA}$ & $\mathrm{NA}$ & $25 \mu \mathrm{m}^{2}$ & $\mathrm{NA}$ \\
{$[8]$} & $\mathrm{NA}$ & $16.83 \mathrm{~dB} / \mu \mathrm{m}$ & $0.08 \mathrm{fJ} / \mathrm{bit}$ & 72 & $0.05 \mu \mathrm{m}^{2}$ & $13.5 \mathrm{~dB}$ \\
{$[9]$} & $1 \mathrm{GHz}$ & $0.16 \mathrm{~dB} / \mu \mathrm{m}$ & $1 \mathrm{pJ} / \mathrm{bit}$ & $\mathrm{NA}$ & $40 \mu \mathrm{m}^{2}$ & $4 \mathrm{~dB}$ \\
{$[10]$} & $120 \mathrm{GHz}$ & $80 \%$ & $\mathrm{NA}$ & $\mathrm{NA}$ & $60 \mu \mathrm{m}^{2}$ & $2.5 \mathrm{~dB}$ \\
{$[11]$} & $559.2 \mathrm{GHz}$ & $0.54 \mathrm{~dB} / \mu \mathrm{m}$ & $1.23 \mathrm{fJ} / \mathrm{bit}$ & 2706 & $1.5 \mu \mathrm{m}^{2}$ & $0.002 \mathrm{~dB}$ \\
{$[12]$} & $759.85 \mathrm{GHz}$ & $0.834 \mathrm{~dB} / \mu \mathrm{m}$ & $0.61 \mathrm{fJ} / \mathrm{bit}$ & 2105 & $0.94 \mu \mathrm{m}^{2}$ & $0.00166 \mathrm{~dB}$ \\
{$[13]$} & $54.85 \mathrm{GHz}$ & $0.4474 \mathrm{~dB} / \mu \mathrm{m}$ & $\mathrm{NA}$ & 2480 & $\mathrm{NA}$ & $0.00247 \mathrm{~dB}$ \\
This work & $\mathrm{NA}$ & $1.2388 \mathrm{~dB} / \mu \mathrm{m}$ & $1 \mathrm{fJ} / \mathrm{bit}$ & $25 \sim 400$ & $\mathrm{NA}$ & $0.0029 \sim 0.0366 \mathrm{~dB} / \mu \mathrm{m}$ \\
\hline
\end{tabular}

Open Access This article is licensed under a Creative Commons Attribution 4.0 International License, which permits use, sharing, adaptation, distribution and reproduction in any medium or format, as long as you give appropriate credit to the original author(s) and the source, provide a link to the Creative Commons licence, and indicate if changes were made. The images or other third party material in this article are included in the article's Creative Commons licence, unless indicated otherwise in a credit line to the material. If material is not included in the article's Creative Commons licence and your intended use is not permitted by statutory regulation or exceeds the permitted use, you will need to obtain permission directly from the copyright holder. To view a copy of this licence, visit http://creativecommons. org/licenses/by/4.0/.

\section{References}

1. M. Liu, X. Yin, E. Ulin-Avila, B. Geng, T. Zentgraf, L. Ju, F. Wang, X. Zhang, A graphene-based broadband optical modulator. Nature 474, 64-67 (2011)

2. M. Tamagnone, A. Fallahi, J.R. Mosig, J. Perruisseau-Carrier, Fundamental limits and near-optimal design of graphene modulators and non-reciprocal devices. Nat. Photonics 8(7), 556-563 (2014)

3. Z. Fang, Y. Wang, A.E. Schlather, Z. Liu, P.M. Ajayan, F. de Javier Garcia Abajo, P. Nordlander, X. Zhu, N.J. Halas, Active tunable absorption enhancement with graphene nanodisk arrays. Nano Lett. 14, 299-304 (2014)

4. K.I. Bolotin, K.J. Sikes, Z. Jiang, M. Klima, G. Fudenberg, J. Hone, P. Kim, H.L. Stormer, Ultrahigh electron mobility in suspended graphene. Solid State Commun. 146, 351-355 (2008)

5. X. Du, I. Skachko, A. Barker, E. Andrei, Approaching ballistic transport in suspended graphene. Nat. Nanotechnol. 3, 491-495 (2008)

6. S. Qu, C. Ma, H. Liu, Tunable graphene-based hybrid plasmonic modulators for subwavelength confinement. Sci. Rep. 7, 5190 (2017)

7. M. Fan, H. Yang, P. Zheng, G. Hu, B. Yun, Y. Cui, Multilayer graphene electro-absorption optical modulator based on doublestripe silicon nitride waveguide. Opt. Express 25(18), 21619-21629 (2017)
8. J. Gosciniak, D.T. Tan, Graphene-based waveguide integrated dielectric-loaded plasmonic electro-absorption modulators. Nanotechnology 24(18), 185202 (2013)

9. M. Liu, X. Yin, X. Zhang, Double-layer graphene optical modulator. Nano Lett. 12(3), 1482-1485 (2012)

10. S.J. Koester, M. Li, High-speed waveguide-coupled graphene-ongraphene optical modulators. Appl. Phys. Lett. 100(17), 171107 (2012)

11. J. Liu, Y. Liu, Ultrafast suspended self-biasing graphene modulator with ultrahigh figure of merit. Opt. Commun. 427, 439-446 (2018)

12. J. Liu, Z.U. Khan, S. Sarjoghian, Suspended triple-layer graphene modulator with two modulation depths and ultra-high modulation speed. OSA Contin. 2(3), 827-838 (2019)

13. J. Liu, Z.U. Khan, S. Sarjoghian, Suspended graphene doublelayer modulator with an ultrahigh figure of merit and a subwavelength thickness modulator with leaky mode. Appl. Opt. 58(14), 3729-3734 (2019)

14. N.K. Emani, T.F. Chung, X.J. Ni, A.V. Kildishev, Y.P. Chen, A. Boltasseva, Electrically tunable damping of plasmonic resonances with graphene. Nano Lett. 12, 5202-5206 (2012)

15. H. Liang, S. Ruan, M. Zhang, H. Su, I.L. Li, Graphene surface plasmon polaritons with opposite in-plane electron oscillations along its two surfaces. Appl. Phys. Lett. 107, 091602 (2015)

16. V.P. Gusynin, S.G. Sharapov, J.P. Carbotte, Magneto-optical conductivity in graphene. J. Phys. Condens. Matter 19, 026222 (2007)

17. R. Mendis, D. Grischkowsky, THz interconnect with low-loss and low-group velocity dispersion. IEEE Microw. Wirel. Compon. Lett. 11(11), 444-446 (2001)

18. J. Liu, H. Liang, M. Zhang, H. Su, THz wave transmission within the metal film coated double-dielectric-slab waveguides and the tunable filter application. Opt. Commun. 351, 103-108 (2015)

19. G.D. Wilk, R.M. Wallace, J.M. Anthony, High-к gate dielectrics: current status and materials properties considerations. J. Appl. Phys. 89(10), 5243-5275 (2001)

Publisher's Note Springer Nature remains neutral with regard to jurisdictional claims in published maps and institutional affiliations. 